\title{
Role of Community Health Clinic on Maternal Health: A Study on Sylhet City of Bangladesh
}

\author{
Ashis Kumer Banik ${ }^{1 *}$, Rafia Tasnim², Mufti Nadimul Quamar Ahmed ${ }^{3}$, Golam Moula ${ }^{3}$, \\ Sharmin Akther ${ }^{3}$ \\ ${ }^{1}$ Lecturer, Department of Sociology, Shahjalal University of Science and Technology (SUST), Bangladesh \\ ${ }^{2}$ B.S.S (Honours) Student, Department of Sociology, SUST, Bangladesh \\ ${ }^{3}$ M.S.S Student, Department of Sociology, SUST, Bangladesh
}

*Corresponding Author: Ashis Kumer Banik, Lecturer, Department of Sociology, Shahjalal University of Science and Technology (SUST), Bangladesh

\begin{abstract}
This paper examines the role of Community Health Clinic on maternal health in Sylhet area of Bangladesh. The present study has been taken "SurjerHashi Clinic" as a case and tried to explore its role over maternal health from the viewpoint of women clients, who receive services from this clinic. Both government and non-governmental organizations (NGO's) have been trying to reduce maternal death and improve maternal health as well as the health of the newborn baby. The present study is descriptive in nature where 35 women have been chosen purposively on the basis of their availability to take part in this study. Our study reveals that most of the respondents (88.5\%) received any type of services during their last pregnancy period for both child health and maternal health from this community clinic. A larger proportion of the respondent came to this clinic during their motherhood and most of them took approximately 2-4 vaccinations. Majority of the participants thinks that doctors are capable to identify patient's illness properly and they give much importance to hearing problems before starting the treatment. A large proportion of the respondents also agreed that there are adequate doctors and staffs available in this community clinic. Furthermore, the study reveals that $54.3 \%$ of respondents are fully satisfied with the services and role that the community clinic has been provided to them. $34.3 \%$ are somewhat satisfied. In contrast, $11.4 \%$ are found not satisfied at all. Community health clinic has a significant role to ensure proper health services for both the mother and their child. This study recommends further detail study taking a broad research area to investigate whether community clinic services can really satisfy and meets the need of poor and rural women who require door-to-door services.
\end{abstract}

Keywords:Community Health Clinic, Surjer Hashi Clinic, Maternal Health

\section{INTRODUCTION}

Due to the strong allegiance to implement the MDG goals, the issue of Maternal health improvement is particularly important for Bangladesh. Since 1990, the country experienced a progressive decline in the Maternal Mortality Rate (MMR) at a rate of 5.6\%, slightly higher than the expected rate $(5.5 \%)$. According to BMMS (2016), the MMR encounters a sheer drop to 194 from 322 over a span of ten years (2001-10). However, improvement it may suggest, Bangladesh still holds the phenomenal rate of adolescent motherhood. More than 30 percent of teenagers have already delivered their first child that results in exorbitant MMR for adolescents doubling the national figure (UNICEF, 2007).

The maternal mortality ratio (MMR) signifies the ratio between the number of maternal deaths and live births. Being a signatory of UN Millennium goals, the country requires to seriously consider the MMR index to gain momentum towards achieving the fifth MDG within 2015. Starting with 574 in 1990, the index approaches to 194 in 2010 marking the decline of more than 65 percent deaths. Among the other causes, the maternal death alone consists of approximately 14 percent of deaths of women in reproductive age (15-49) (Roy, A and Shengelia, L., 2016).

Globally, in the case of maternal care, skilled health personnel assisted nearly three quarter of births in 2014 alone, indicating a substantial increase from 59 percent in 1990. However, in the developing countries, the availability of such assistance is dependent upon the spatial settings. In rural areas, 
merely 56 percent of childbirths get skilled health assistance as compared to 87 percent in urban areas. Moreover, barely 50 percent expectant mothers receive four recommended ante-natal care visits. The below figure shows maternal mortality ratio in 1990 and 2013 of different regions of the world (Figure 1).

To provide free services at their doorstep, the government of Bangladesh revived the community clinic project for rural inhabitants from which more than 10,000 local people received basic health care service till the date. (Karim et al., 2016). The Community Clinic (CC) is a unique extension of Primary Health Care services which the lowest tier health facility at the primary level established throughout the country including very hard-to-reach, remote \& isolated areas. The construction of CC establishment started in 1998. At present 13,136 CCs are on board and the number is gradually increasing. From 2009-2015, 460.88 million visits were made to CCs for services of which 9.071 million emergency \& complicated cases were referred to higher facilities for proper management. Among the service seekers, about $80 \%$ are women and children. On average 9.5-10 million visits are in CCs per month \& 38 visits per day per CC (Rahman, B., 2017).

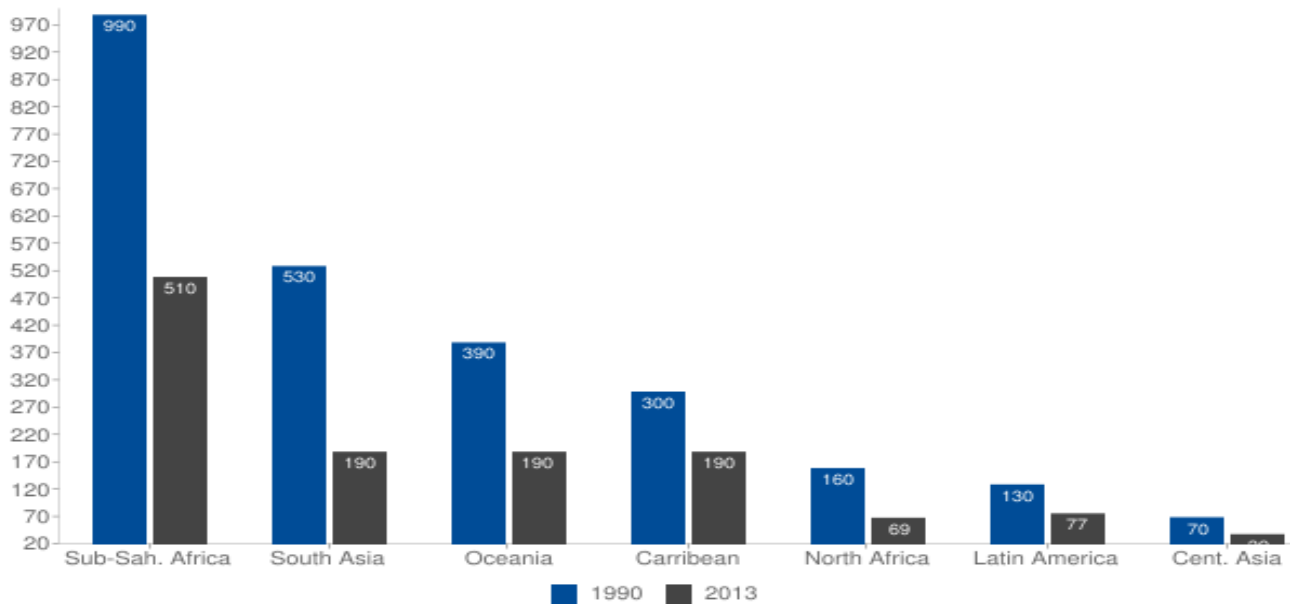

Figure1.Maternal mortality ratio, 1990 and 2013 (maternal deaths per 100,000 live births, women aged 15-49)

Source: The Millennium Development Goals Report (2015)

Community health clinic is formed to progress the health condition of the people specifically, for women and children in rural areas. These clinics are basically situated in the rural areas of the underdeveloped or developing countries. The system of community health clinics in Bangladesh is contributing largely to improve the public health status of rural communities in Bangladesh. The significant success of this health promotion program leads medicine to its summit of power to influence the prevalent power structure in rural Bangladesh. The broad objective of this study is to explore the role of community health clinic on maternal health from the perspective of clients who receive services from these community clinics. This research is also an attempt to know about the services provided by community health clinics in Bangladesh. Bangladesh is now on the way of proving himself as a developing country in the world. Health is one of the most important issues. Community health clinics have been established to improve the health condition of rural people, specially, the health condition of women and children. Therefore, conducting this type of study is very logical and fruitful in order to explore the role of community health clinic on maternal health.

\section{RELEVANT LiTERATURES}

Maternal health encompasses the healthcare dimensions of family planning, preconception, prenatal and postnatal care in order to ensure a positive and fulfilling experience in most cases and reduce maternal morbidity and mortality in other cases (WHO, 2018a). According to the key findings of World Health Organization (WHO, 2018a); Every day, approximately 830 women die from preventable causes related to pregnancy and childbirth.99\% of all maternal deaths occur in developing countries. Maternal mortality is higher in women living in rural areas and among poorer communities. Young adolescents face a higher risk of complications and death as a result of pregnancy than other women. Between 1990 and 2015, maternal mortality worldwide dropped by about 44\%. Between 2016 and 2030, as part of the Sustainable Development Goals, the target is to reduce the global maternal mortality ratio to less than 70 per 100000 live births. 
In Bangladesh, since 2009 the establishment of 14, 000 community clinics (CCs) for every 6,000 population across the country brings health care to the community doorstep. Now, people can avail of health, family planning and nutrition services under one roof and within half an hour walking distance from their homes even in remote areas. CCs have contributed significantly to the improvement of the overall antenatal and postnatal care in Bangladesh. The clinics provide counselling on reproductive health and consequences of early marriage, and also supply contraceptives as well as care for pregnant women. Treatment is also provided for diarrhoea, pneumonia and other childhood infections. (WHO,2018b).

\section{Methodology}

Descriptive research design was followed in this study which is one of the most commonly used research designs in social research to describe situations and events through studies (Babbie, 2004, p. 89; Islam, 2011, p. 87). Based on the research objectives, quantitative method has been followed to conduct this study. Quantitative research is the systematic investigation of quantitative properties and phenomena as well as their interrelationships. It is widely used in both natural sciences and social sciences from physics and biology to sociology and journalism (Islam, 2011, p. 22). "SURJER HASHI CLINIC" is a very well-known community clinic throughout the country which aim is to provide different services basically to women and children. This study is conducted on these clients (women) who takes different services from the aforementioned clinic from their two-branch situated in Sylhet (Tuker Bazar and Mirja-jangal). In this study, we labelled Tuker Bazar branch as Branch 1 and Mirja-Jangal branch as Branch 2 for the simplicity of describing our findings. These two areas have been selected purposively based on the quick and easy access and to reduce time. This study is conducted 2 months long; from January 10, 2018 to March 10 2018. Every day, huge numbers of women are coming to this clinic for taking different services that they usually provide. As, it is almost impossible to collect data from every woman who receive any service, this study incorporates data from 35 women who receive any services from this clinic (these two branches) during January 2018March 2018. Respondents are chosen purposively who are willing to participate and give their verbal consent after hearing our research aims and objectives. First of all, Women were interviewed about their demographic and socio-economic condition, what facilities did they received from the community clinic during their pregnancy and after the childbirth, what they think about service delivery of community clinic and how much they satisfied with receiving these facilities. This study was conducted with help of survey method where a standard questionnaire was provided to the respondents for collecting data containing maximum close-ended questions. Some questions were remaining open-ended too for knowing respondent's views, comment or opinions on that particular topic or question. Questions were formed in an easy \& understandable way so that, the respondents can easily provide their answer. If a respondent feels any problems or confusions to understand any question, the researcher repeated that question \& make it clear to him/her. Data have been analysed in accordance with the objectives of this study. These analyses have been done in quantitatively. The quantitative data have been analysed by using different statistical tools and techniques such as frequency, mean, standard deviation, percentage etc. These outputs are presented in this paper with the expression of different tables, box, bar graph etc. SPSS (Statistical Package for Social Sciences) version 22 and Microsoft Excel were used to analyse the quantitative data.

\section{FINDINGS}

\subsection{Major Socio-Demographic Characteristics of the Respondents are Present and Discuss Below}

\subsubsection{Distribution of the Respondents by Taking Services from the Community Clinic by branch}

Table1.Respondents taking services from CC branch

\begin{tabular}{|c|c|c|c|}
\hline & \multicolumn{2}{|c|}{ SURJHER HASHI COMMUNITY CLINIC } & \multirow{2}{*}{ Total \% (N) } \\
\cline { 2 - 3 } & Branch 1 \% (n) & Branch 2 \% (n) & \\
\hline Respondents & $54.3(19)$ & $45.7(16)$ & $100(35)$ \\
\hline
\end{tabular}

The study purposively incorporated participants from two locations under study; Branch 1 and Branch 2. On the basis of availability and informed consent, the former constitutes around 54\% while the latter constitutes the rest of the respondents. 


\subsubsection{Distribution of the Respondents by Religion}

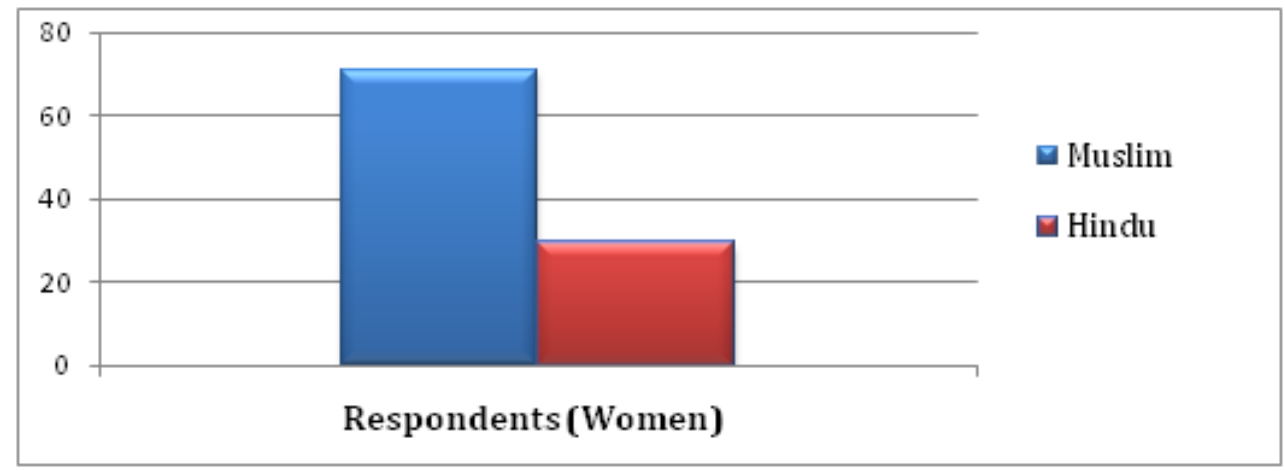

Figure2. Religion of the respondents

The graphical representations signify the dominant number of Muslim women(70\%) over the Hindu women $(30 \%)$.

\subsubsection{Distribution of the Respondents by Age Group}

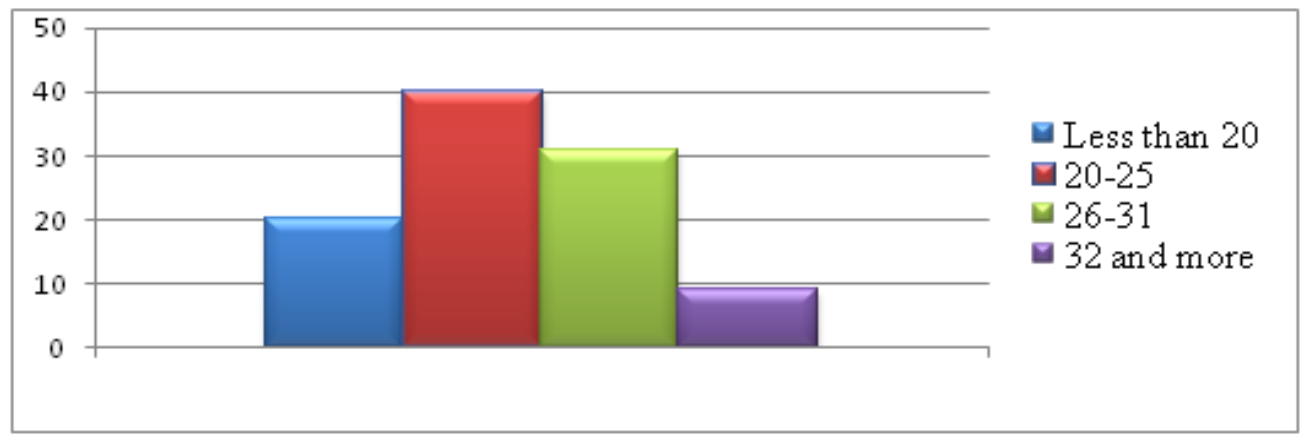

Figure3. Age group of the respondents

The above graph indicates that highest percentage of the respondents are belonging to the second age category that is $20-25$ comprising $40 \%$. $31 \%$ of the respondents are belonging to the 26-31 age category. Only $9 \%$ respondents are belonging 32 or more years age category.

\subsubsection{Distribution of the Respondents by their Family Size}

Table4. Family type of the respondents

\begin{tabular}{|c|c|c|c|c|}
\hline Categories & $\begin{array}{c}\text { Respondents } \\
\text { \% (n) }\end{array}$ & Mean & Min. & Max. \\
\hline Small Family (2-4) & $20.0(7)$ & 5.20 & 2 & 9 \\
\hline Medium Family (5-7) & $57.1(20)$ & & & \\
\hline Large Family (8+) & $22.9(8)$ & & & \\
\hline Total \% (N) & $100(35)$ & & & \\
\hline
\end{tabular}

According to the table above, medium size family (57.1 percent) seems more dominant against small size and large size family. Narrow percentage of respondents yields small family size consisting of 7 members. Almost 23\% respondents have large family size. On an average, families make up 5.20 members. The above table 4 also depicts the minimum, maximum and mean family size found in this study.

\subsubsection{Distribution of the Respondents by Educational Level}

Table5. Educational level of the respondents

\begin{tabular}{|c|c|c|c|c|}
\hline Categories & Respondents \%(n) & Mean & Min. & Max. \\
\hline Can't read and write $(0)$ & $17.1(6)$ & \multirow[t]{5}{*}{5.31} & \multirow[t]{5}{*}{0} & \multirow[t]{5}{*}{14} \\
\hline Primary (1-5) & $28.6(10)$ & & & \\
\hline Secondary (6-10) & $42.9(15)$ & & & \\
\hline Higher Secondary (11 and More) & $11.4(4)$ & & & \\
\hline Total \% (N) & $100(35)$ & & & \\
\hline
\end{tabular}


The above table signifies that majority of the respondents comprising almost $43 \%$ have received secondary education while $17.1 \%$ percent respondents have no formal education at all. Additionally, $28.6 \%$ respondents have primary education and only 11.4 percent of the respondents have competed their higher secondary education. Collectively, the mean score for the education level figures 5.31 which indicates most of the respondents have completed almost their primary education. Maximum years of schooling found in this study is 14 .

\subsubsection{Distribution of the Respondents by Income}

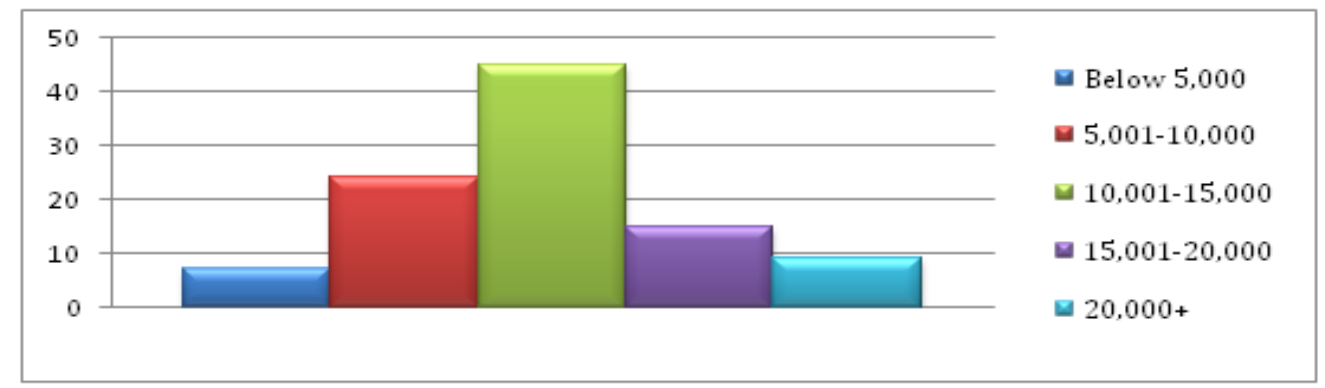

Figure4. Income of the respondents

Regarding income, the above figure shows that majority of the respondents earn between 10,001 and 15,000 BDT $(45 \%)$. On the other hand, $7 \%$ respondents have below 5,000 earning. $24 \%$ respondents have 5,001-10,000 BDT monthly earning. Moreover, 9\% earns more than 20,000 BDT per month.

\subsection{Services Received from the Community Clinic}

Table6. Different services taken from the community clinic

\begin{tabular}{|c|c|}
\hline Items & $\%(\mathrm{n})$ \\
\hline $\begin{array}{l}\text { Did you come to this community clinic during your last pregnancy to receive any } \\
\text { services? } \\
\text { 1. Yes } \\
\text { 2. No } \\
\text { (If yes) How often you came? } \\
\text { 1. Very frequently } \\
\text { 2. Frequently } \\
\text { 3. Very rarely } \\
\text { Type of service(s) that you actually wanted to receive } \\
\text { 1. Child Health } \\
\text { 2. Maternal Health } \\
\text { 3. Both } \\
\text { Did you come to this community clinic for the vaccination during your motherhood? } \\
\text { 1.Yes } \\
\text { 2. No } \\
\text { (If yes) Number of vaccination (s) that you received } \\
\text { 1. Only } 1 \\
\text { 2. } 2 \text {-4 } \\
\text { 3. } 5 \text { and more } \\
\text { Did you get all services properly? } \\
\text { 1.Yes } \\
\text { 2. No } \\
\text { Did you come this community clinic after the birth of your baby? } \\
\text { 1.Yes } \\
\text { 2.No } \\
\text { (If Yes) How often you came? } \\
\text { 1. Very frequently } \\
\text { 2. Frequently } \\
\text { 3. Very rarely } \\
\text { Goes the community clinic offer you to provide any financial support given by } \\
\text { 1.Yes } \\
\text { 2.No }\end{array}$ & $\begin{array}{c}85.7(30) \\
14.3(5) \\
13.3(4) \\
73.3(22) \\
13.3(4) \\
\\
82.9(29) \\
17.1(6) \\
17.6(31) \\
11.8(4) \\
32.2(10) \\
54.8(17) \\
12.9(4) \\
\\
82.9(29) \\
17.1(6)\end{array}$ \\
\hline
\end{tabular}

Source: Field Survey (2018) 
The community clinic under investigation evidently appears to have rendered satisfactory maternal services to the expectant mothers. The table above suggests that most of the respondents $(88.5 \%)$ visited their respective clinics during their last pregnancy terms with increased frequency. Literally, nearly 90 percent of them visited very frequently $(22.6 \%)$ and frequently $(64.5 \%)$ as compared to the rarely (12.9\%). Their visits intend to access child (11.4\%), maternal care (17.2\%) and both $(71.4 \%)$. Further, the expectants were vaccinated in a large margin (85.7\%); among them, most of them visited $2-4$ times $(73.3 \%)$ and $13.3 \%$ visited only once and the rest $13.3 \%$ visited more than 4 times during their terms of pregnancy to avoid pregnancy-related complications. When asked, more than threefourth $(82.9 \%)$ participants responded that they received proper attention by the clinics`doctors and staffs. Such an immense satisfaction led them to visit the clinics for post-natal care. Around $88.6 \%$ of them visited the clings after giving the birth of their children. Among them, 32.2\% visited very frequently and $54.8 \%$ visited frequently as compared to $12.9 \%$ rarely visited. The clinics provided the government-initiated financial support to the needy clients. The participants involved in the study confirmed that they received such support in a huge margin(82.9\%).

\subsection{Perceptions about the Role and Services Delivered by the Community Clinic}

The table below encompasses the participants 'perception towards the doctors and the staffs involved in the health care facilities. The investigation finds a widely-held commendatory perception towards the community clinic services among the studied sample in many respects. Most of the respondents yield positive response to the doctors ' capability to properly detect illness causing sufferings to them. Exactly $22.9 \%$ strongly agreed and nearly 50 percent agreed to the fact while merely $5.7 \%$ disagreed with $22.9 \%$ being neutral. In case of attention received by the expectants, $22.9 \%$ strongly agrees and $40 \%$ agrees that the doctors pay them the required attention by hearing their problems patiently as compared to the $17.1 \%$ disagreed and $8.6 \%$ strongly disagreed. Furthermore, $17.1 \%$ strongly agreed and $34.3 \%$ agreed that the clinic provide all necessary services required for health assistance during and after the pregnancy period. Contrarily, $22.9 \%$ disagreed and $11.4 \%$ strongly disagreed that the clinics provide services properly. In case of availability of drugs, $40 \%$ strongly agreed and $22.9 \%$ agreed that prescribed drugs are easily accessible as compared to the $11.4 \%$ disagreed and $20 \%$ strongly disagreed. Regarding the staffs' cooperation, most of the respondents (14.3\% strongly agreed and $51.4 \%$ agreed) showed positive responses while $20 \%$ disagreed and $5.7 \%$ strongly disagreed with it. However, the participants yield negative responses towards the availability of doctors. Exactly $45.7 \%$ strongly agreed and $20 \%$ agreed that the number of doctors is insufficient against the increasing number of clients. Only $8.6 \%$ strongly and $25.7 \%$ disagreed with it. A mix reaction has been found towards the adequacy of staff numbers. $14.3 \%$ strongly and $20 \%$ agreed that the staffs were adequate in numbers while $28.6 \%$ disagreed and $25.7 \%$ strongly disagreed. With respect to distance, $51.4 \%$ strongly agreed and $14.3 \%$ agreed that the health care facilities are easily approachable from their respective homes. Finally, 22.9\% strongly and 34.3\% agreed that they had received the service at a reasonable cost while $20 \%$ disagreed and $8.5 \%$ strongly disagreed with it.

Table7. Perceptions about community clinics role

\begin{tabular}{|l|c|c|c|c|c|}
\hline \multicolumn{1}{|c|}{ Statements } & \multicolumn{5}{|c|}{ \% (n) } \\
\cline { 2 - 6 } & $\begin{array}{l}\text { Strongly } \\
\text { Agree(5) }\end{array}$ & $\begin{array}{c}\text { Agree } \\
\text { (4) }\end{array}$ & $\begin{array}{c}\text { Neutral } \\
\text { (3) }\end{array}$ & $\begin{array}{c}\text { Disagree } \\
\text { (2) }\end{array}$ & $\begin{array}{c}\text { Strongly } \\
\text { Disagree(1) }\end{array}$ \\
\hline Doctors are capable to identify patient's illness properly & $22.9(8)$ & $48.5(17)$ & $22.9(8)$ & $5.7(2)$ & $0(0)$ \\
\hline $\begin{array}{l}\text { Doctors give much importance on hearing patients } \\
\text { problem first }\end{array}$ & $22.9(8)$ & $40.0(14)$ & $11.4(4)$ & $17.1(6)$ & $8.6(3)$ \\
\hline Community clinic provides all of our required services & $17.1(6)$ & $34.3(12)$ & $14.3(5)$ & $22.9(8)$ & $11.4(4)$ \\
\hline $\begin{array}{l}\text { Here, we can find all the required drugs very easily that } \\
\text { are prescribed by our doctor }\end{array}$ & $40.0(14)$ & $22.9(8)$ & $5.7(2)$ & $11.4(4)$ & $20.0(7)$ \\
\hline Staffs are very co-operative here & $14.3(5)$ & $51.4(18)$ & $8.6(3)$ & $20.0(7)$ & $5.7(2)$ \\
\hline $\begin{array}{l}\text { There are adequate doctors available in this community } \\
\text { clinic }\end{array}$ & $8.6(3)$ & $25.7(9)$ & $0.0(0)$ & $45.7(16)$ & $20.0(7)$ \\
\hline $\begin{array}{l}\text { There are adequate staffs available in this community clinic } \\
\text { There are adequate medicines available in this } \\
\text { community clinic }\end{array}$ & $14.3(5)$ & $20.0(7)$ & $11.4(4)$ & $28.6(10)$ & $25.7(9)$ \\
\hline $\begin{array}{l}\text { We can easily come to this clinic as the distance is not } \\
\text { so high for us }\end{array}$ & $51.4(18)$ & $14.1(6)$ & $5.7(2)$ & $45.8(16)$ & $20.0(7)$ \\
\hline Cost for getting services is reasonable for us & $22.9(8)$ & $34.3(12)$ & $14.3(5)$ & $20.0(7)$ & $8.5(3)$ \\
\hline
\end{tabular}

Source: Field Survey (2018)

International Journal of Research in Sociology and Anthropology (IJRSA)

Page | 39 


\subsection{Overall satisfaction about the services and role of the community clinic}

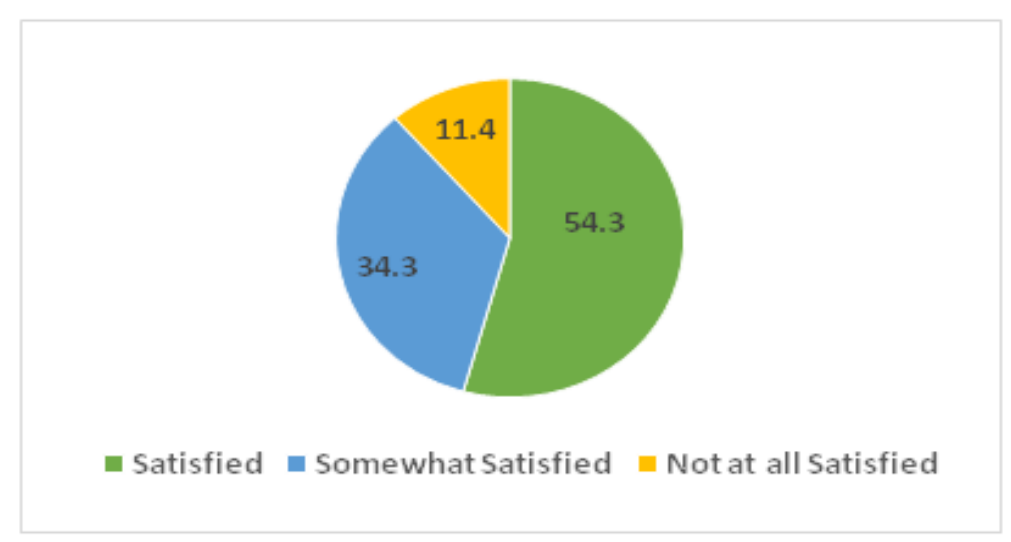

Figure5. Level of satisfaction of the respondents

The table above suggests that more than half of the participants (54.3\%) are apparently satisfied with the performance of the clinical care for maternal services while merely an insignificant proportion expresses dissatisfaction.

\section{Conclusions}

The study clearly indicates the progresses and prospects that will have significant consequences upon the achievement of Sustainable Development Goals (SDG) in terms of maternal health. In conjunction with distributing the financial support provided by Government, the study suggests the health care facility satisfied more than three-fourth $(82.9 \%)$ patients with their proper medical assistance during the pregnancy period. Approximately 90 percent participants paid a frequent visit to the facility in order to receive both maternal and child care. Moreover, the significant proportion of the serviceholder has been vaccinated 2 to 4 times to avoid pregnancy-related complications. Fortunately, a fairly significant segment of participants received rapt attention and active cooperation from the doctors and the clinic staffs in rendering essential services. The easily approachable services with reasonable costs triggered an enormous popularity for these non-profit entities among the participants. However, the analysis indicates the existence of a sense of deep concern over the adequacy of doctors and staffs against the burgeoning demands. This study recommends further detail study taking broad research area to investigate whether community clinic services can really satisfy poor and rural women who requires door-to-door services.

\section{ACKNOWLEDGEMENT}

At first, we would like to express our sincere gratitude to Almighty ALLAH, on whom we depend for sustenance, guidance and everything. We also would like to say 'thanks' to our all participants who have made this study successful by providing valuable information, opinions and most importantly for giving us their valuable time. Lastly, we would also like to show our gratitude to Sayed Bokth Mojumadar for his continuous support from the very beginning of this study.

\section{REFERENCES}

[1] UNICEF (2007). Maternal Health in Bangladesh available at https://www.unicef.org/bangladesh/ MATERNALHEALTH.pdf

[2] GoB (2015). Millennium Development Goals Bangladesh progress report, General Economics Division (GED), Planning Commission.

[3] Roy, A \&Shengelia, L. (2016). An Analysis on Maternal Healthcare Situation in Bangladesh: A Review, Diversity and Equality in Health and Care, 13(5): 360-364.

[4] UN (2015). The Millennium Development Goals Report, United nations: New York.

[5] Rahman, B. (2017). Community Clinic in Bangladesh: Taking Health Services to Rural People retrieved on 15 April 2018 from http://www.daily-sun.com/printversion/details/265214/Community-Clinic-inBangladesh: Taking-Health-Services-to-Rural-People.

[6] Karim, R. M., Abdullah, M.S., Rahman, A. M. and Alam, A.M. (2016). Identifying role of perceived quality and satisfaction on the utilization status of the community clinic services; Bangladesh context, BMC Health Services Research, DOI: 10.1186/s12913-016-1461-z

[7] Babbie, E. (2004). The Practice of social Research (10th ed.). Belmont, U.S.A.: Thomson Learning. 
[8] Islam, M.N. (2008). An introduction to research method (2nd ed). Dhaka, Bangladesh: Mullick\& Brothers.

[9] World Health Organization (WHO) (2018a). Maternal mortality available at http://www.who.int/en/newsroom/fact-sheets/detail/maternal-mortality.

[10] World Health Organization (WHO) (2018b). Community clinics in Bangladesh: Bringing health care to the doorsteps of rural people. Available athttp://www.searo.who.int/mediacentre/events/communityclinics-bangladesh-story/en/.

Citation: Ashis Kumer Banik et.al. "Role of Community Health Clinic on Maternal Health: A Study on Sylhet City of Bangladesh" International Journal of Research in Sociology and Anthropology (IJRSA), vol 4, no. 3, 2018, pp. 34-41.doi:http://dx.doi.org/10.20431/2454-8677.0403004.

Copyright: (C) 2018 Authors. This is an open-access article distributed under the terms of the Creative Commons Attribution License, which permits unrestricted use, distribution, and reproduction in any medium, provided the original author and source are credited. 